\title{
Cooperação econômica versus competitividade social
}

\author{
João Cláudio Tupinambá Arroyo \\ Faculdade do Pará (FAP)
}

\section{Cooperação econômica versus competitividade social}

Resumo: As estratégias de cooperação econômica, presentes desde as sociedades primitivas, indicam que a presidência da lógica da 'competição' é uma importante distorção promovida pelo modo capitalista de produção e vivência que apartou o trabalhador do trabalho, desumanizando as relações sociais e políticas. Cooperação e competição possuem interações e complementaridades possíveis de potencializar um desenvolvimento humano desde que sob as premissas da economia solidária. Interação que traz efetiva agregação de valor ao processo econômico. A principal estratégia cooperativa está na lógica das teorias que fundamentam os aglomerados e arranjos econômicos. E a construção sociocultural capaz de tornar esta opção uma construção hegemônica se articula, hoje, em torno da economia solidária.

Palavras-chave: economia solidária, aglomerados econômicos, cooperação, competitividade.

\section{Economic Cooperation Versus Social Competitiveness}

Abstract: The strategies of economic cooperation, found since primitive societies, indicate that the dominance of the logic of 'competition" is an important distortion promoted by the capitalist mode of production and the experience that separated the worker from work, dehumanizing social and political relations. Cooperation and competition interact and complement each other in ways that are capable of potentializing human development as long as they do so from the premises of solidarity economics. This interaction effectively aggregates value to the economic process. The principal cooperative strategy is in the logic of the theories that are at the foundation of the economic agglomerates and arrangements. The social-cultural construction capable of making this option a hegemonic construction is now articulated around solidarity economics.

Key words: solidarity economics, economic agglomerates, cooperation, competitiveness. 


\section{Introdução}

Observa-se na sociedade brasileira, sem mencionar outras, que, ao mesmo tempo em que o modo capitalista de vida aprofunda o individualismo, o egoísmo, a ganância, a competição pura e a concentração de renda e poder, proliferam iniciativas solidárias que vão bem além da tradição da filantropia. Tradição que já não é pouca, se contarmos o sem-número de iniciativas institucionais e anônimas que indivíduos, famílias e grupos de afinidade passam a assumir autonomamente.

No seio da sociedade civil, o crescimento ${ }^{1}$ do voluntariado, da responsabilidade social, da ação social das igrejas e da organização dos próprios setores populares excluídos chama nossa atenção para o descontentamento das pessoas com o modo de vida propiciado pelo sistema econômico capitalista.

A formação de ONGs, e outras organizações atribuídas ao 'terceiro setor', quer pela motivação social ou ambiental, coloca-se como mais um indicador deste descontentamento, agora em um patamar de percepção maior do que as manifestações difusas na sociedade. As ONGs, tanto entre as organizações que pretendem apenas amenizar os efeitos perversos do capitalismo quanto as que têm em perspectiva a superação definitiva destes efeitos, constituem um espaço sociopolítico novo de institucionalização de interesses públicos não-estatais. Ainda que as denominações 'não governamental' e 'terceiro setor' ${ }^{2}$ digam pouco sobre a definição e pluralidade deste fenômeno, fica claro o descontentamento com o papel do Estado sob este modo de produção e vida em que nos encontramos.

No Brasil, as ONGs, particularmente as vinculadas ao campo organizado pela Associação Brasileira de Organizações Não Governamentais (ABONG), são uma expressão eloqüente de possibilidades de cooperação institucional nacional e internacional. Desde a década de 1960, elas vêm gerando novos espaços de sociabilidade, de educação política, através de metodologias de 'educação popular' 3 e de avanços na direção do 'controle social'4 sobre o Estado, visando influir nas políticas públicas para diminuir a exclusão e permitir o aperfeiçoamento da democracia.

No plano institucional econômico, as cooperativas - possibilidade de organização social e de produção que foi derrotada pela hegemonia capitalista desde o século 19, permanecem como alternativas que se mantêm dando viabilidade econômica a grupos sociais antes excluídos e até reabilitando empresas falidas, que passam a ser gerenciadas pelos seus trabalhadores cooperados, sob autogestão ${ }^{5}$. Sob empreendimentos em regime de autogestão, apenas no âmbito da Associação Nacional de Trabalhadores e Empresas de Autogestão (ANTEAG, 2007), estão "mais de 32 mil postos de trabalho. Apenas de 1999 a 2001, foram reestruturados 420 empreendimentos em áreas de 129 municípios brasileiros."

O exemplo mais eloqüente desta possibilidade é a experiência tida em Mondragón, na Espanha. Do trabalho iniciado pelo jesuíta Dom José Maria Arizmendiarrieta (1915-1976) - que, na década de 1940, ao mesmo tempo em que ensinava aos jovens um ofício também ensinava gerência e ética -, hoje o complexo cooperativo de Mondragón ultrapassou os 22 mil cooperados em mais de 100 cooperativas do grupo, movimentando mais de 2,6 bilhões de dólares anuais.

O segredo de D. José? A percepção dos atributos locais; uma região basca que sob pressão do governo espanhol desenvolveu "um povo esforçado e trabalhador, uma solidariedade baseada nos maus-tratos do governo e uma forte estrutura social" (BARKER, 1997, p. 35). Somou a isso uma respeitável reputação do trabalho que realizava com os jovens para enfrentar um desemprego de $20 \%$ e uma estratégia de marketing capaz de mobilizar a sociedade local que, mesmo com suas dificuldades, arrecadou cerca de 360 mil dólares para que iniciassem um negócio. Ou seja, o segredo não é segredo, é teoria. A teoria da "causação circular cumulativa" de Myrdal (1965) nos ajuda a entender o exemplo.

Assim, exatamente no período em que o neoliberalismo ${ }^{6}$ grassava no mundo - na segunda metade do século 20 - o complexo cooperativo de Mondragón "cresceu e desenvolveu uma democracia trabalhista única, na qual os funcionários eram donos das empresas, a relação capital-trabalhador foi invertida e o espírito empreendedor florescia num ritmo de sucesso sem igual"' (BARKER, 1997, p. 37). E o autor prossegue, referindo-se à estrutura financeira e ao fundo acumulado:

Antes de mais nada todos os trabalhadores participam com recursos financeiros próprios na cooperativa da qual fazem parte. [...]. Em segundo lugar, foi criado um banco cooperativo para atender à cooperativa. Sua missão é muito clara: financiar novos empregos de forma que todas as pessoas que desejem trabalhar na região de Mondragón possam fazê-lo. Essa missão é mais importante do que conseguir o melhor retorno sobre o investimento, violando assim o paradigma predominante das atividades bancárias.

O próprio mercado começa a dar sinais práticos de que os processos de exclusão social e econômica diminuem suas possibilidades de crescimento, mesmo na lógica do lucro crescente. A flexibilização dos critérios de crédito no comércio cresce para recuperar contingentes que a inadimplência colocou para fora; e os parâmetros para acesso a crédito, a partir 
do que já é feito no microcrédito, começam a flexibilizar o paradigma de Basiléia 7 .

As mudanças de critérios já refletem sobre estatísticas interessantes. Existem no país, segundo a empresa de pesquisa de mercado Condere (2007) de São Paulo, 29 milhões de cartões de créditos. Em 2007, apenas $18 \%$ destes estão em mãos das classes de renda A e B. Mais de 18 milhões de cartões de crédito estão nas classes $\mathrm{C}$ e $\mathrm{D}$, entre os que ganham até três salários mínimos. Outra consultoria, a Data Popular (2007) de São Paulo, estimou que 42\% dos que usam cartão de crédito são da classe $\mathrm{C}$ e $29 \%$ da classe D.

Ou seja, por dentro da lógica comercial e capitalista, vai ocorrendo a gestação de uma nova possibilidade. Uma organização social e econômica que começa a buscar na inclusão socioeconômica a solução de seus problemas. Estabelecendo estratégias cada vez mais focadas na cooperação.

A clara tendência a modelos de desenvolvimentos que dão relevância para cadeias, clusters, aglomerados, arranjos e sistemas produtivos, vai aos poucos dando evidência para o papel de estratégias cooperativas na sustentação da sobrevivência de empreendimentos, particularmente os da "economia popular" (ARROYO; SCHUCH, 2006) e, da própria "vantagem competitiva" (PORTER, 1999) de setores e regiões.

E curioso que, em rápidas inserções buscando as raízes da cooperação, encontramos evidências de ser esta, na origem, a nossa tendência natural e/ou preferencial, antes da opção pela competição.

\section{A divisão do trabalho social e a desumanização da economia}

Nossa investigação procurou elementos teóricos para compreender o que se passou, e em que momento, para que a composição cooperação-competição passasse a ser presidida pela competição, distorcendo uma tendência que nos viabilizou como espécie.

Do que entendemos, percebemos que a composição cooperação-competição é inseparável. No entanto, a 'causação circular cumulativa', dos fenômenos sociais, políticos e econômicos, sob a presidência da cooperação é bem diferente da presidida pela competição.

Na origem, viabilizamo-nos pela nossa capacidade de cooperação. Ou seja, foi a cooperação que nos conferiu competitividade diante de espécies predadoras mais aptas. Porque, ao não excluir indivíduos, o rebanho humano tanto crescia em número, quanto pela interação e solidariedade, o que fez a qualidade das relações e laços propiciarem a execução de tarefas mais complexas, capazes de garantir sobrevivência e segurança a todos.

No entanto, à medida que os rebanhos foram se constituindo em sociedades, e as ameaças externas à sobrevivência diminuíram, a competição se colocou como possibilidade de desenvolvimento humano. A latência desta possibilidade se somou à diferenciação de grupos no interior das sociedades que se complexificavam, em estratos e outras subdivisões. Tudo isto se combinou a um longo período histórico obscuro, a Idade Média, quando a dimensão individual ficou marcadamente subordinada aos ditames de uma lógica coletiva muitas vezes perversa, ainda que bastante diferenciada ente os estratos sociais.

Com a Renascença e o Iluminismo, a valoração da dimensão individual ganhou força tanto como filosofia e arte quanto como discurso político, crescendo gradualmente até o marco histórico da Revolução Francesa que cravou definitivamente o tema da liberdade como parâmetro para a recomposição da política, da economia e de outras dimensões sociais.

Surgiram pelo menos duas possibilidades no avanço da valoração da individualidade, solapada na Idade Média. Uma, onde a liberdade individual se articulava à fraternidade e à igualdade, como no ideário republicano da Revolução Francesa. E outra que focava a liberdade individual como direito à iniciativa econômica (a dos burgos ${ }^{8}$ ), pragmaticamente tomada como único caminho para, pelo menos, equilibrar a curto prazo as relações sociais e políticas com uma nobreza opressora, mesmo quando decadente. Como se sabe, a segunda possibilidade hegemonizou a história até aqui.

No entanto, não se pode perder de vista que neste processo a diferenciação da sociedade, que cada vez mais se complexificava, permanecia como elemento estruturante na nova possibilidade que se efetivava. Diferenciação esta que, combinada à valoração da individualidade e à estratégia de recorrer à acumulação econômica para enfrentar a nobreza opressora, foi virando individualismo, tal como o assistimos hoje, reeditando rupturas a partir de grupos e nichos sociais específicos que articulam outras ordens por dentro do Estado, como o fenômeno do crime organizado, das gangues, tribos.

A partir daqui recorreremos a Èmile Durkheim ${ }^{9}$ que em sua primeira grande obra, em1893, apresenta algumas categorias que nos ajudam a entender o desfecho histórico deste período e perscrutar as tendências que vivemos.

Para Durkheim (2007), qualquer agrupamento humano só se constitui em sociedade se for estabelecido algum laço de solidariedade entre os indivíduos para que se originem o pacto de convivência e a ordem social, que deverão ser respeitados por todos.

$\mathrm{Na}$ origem da sociedade, quando se encontravam poucas diferenciações internas, a manutenção dos laços sociais se dava por uma "solidariedade mecânica" (DURKHEIM, 2007), estabelecida exatamente pela semelhança e alta identidade de cultura, crenças e valores, entre seus membros. Com a complexificação da sociedade - pela miscigenação, migração, acordos de 
guerra, entre outros - deu-se uma diferenciação interna em estratos, funções econômicas e papéis sociais, entre indivíduos e pequenos agrupamentos que não mais tinham o mesmo grau de identidade, exigindo uma outra lógica de solidariedade para que se chegasse ao pacto e à ordem social necessários para sua unidade. Neste momento, a solidariedade busca assentar-se exatamente nas diferenças, e não mais na semelhança como antes. Este é o conceito de "solidariedade orgânica" (DURKHEIM, 2007).

A solidariedade orgânica inclui um elemento que ainda não tratamos - a divisão do trabalho. Foi exatamente o processo de complexificação social que propiciou a diferenciação dos indivíduos, por sua função econômica, como uma possibilidade que se tornou efetiva na prática social e um elemento-chave na distribuição de riqueza e poder desde então.

Consideramos que a complexificação da sociedade com sua consequiente diferenciação, no início marcadamente étnica, fez com que na transição entre a solidariedade mecânica, baseada na semelhança, e a solidariedade orgânica, baseada na diferença, ocorresse uma superposição entre diferenciação étnica e diferenciação econômica, social e política. Não por acaso os derrotados nas guerras eram incorporados na sociedade do grupo vitorioso como escravos, cumprindo um papel econômico e político muito específico e marcadamente subalterno. Não por acaso, em período muito mais recente, no Brasil, os pobres de hoje possuem uma expressiva relação étnica com os escravos do período colonial.

Assim, os benefícios da conquista da liberdade, também foram apropriados diferenciadamente. Com a conquista do livre empreender pelos burgueses e a busca de tecnologias, como as que eclodiram a Revolução Industrial, a divisão social do trabalho aprofundou-se atribuindo a cada segmento uma função na engenharia do novo modo produtivo, conseguindo sobreviver a uma contradição intrínseca.

Ao mesmo tempo em que a linha de montagem se decompunha em operações simples, fazendo com que a interdependência entre os indivíduos se evidenciasse, inclusive criando condições para a possibilidade de um aprofundamento da solidariedade, a capacidade produtiva aumentava exponencialmente, sem garantir a sobrevivência e a segurança, principais motivações originais da cooperação, já que a acumulação de capital estava fortemente concentrada entre os burgueses, em uma escala muito maior do que a própria reprodução destes necessitava.

Portanto, ao mesmo tempo em que se operava a "solidariedade orgânica" (DURKHEIM, 2007) entre diferentes, para a unidade da sociedade sob um mesmo Estado, no plano econômico, a partição desigual se aprofundava aceleradamente com uma densidade que acabou por fazer com que tudo o mais lhe gravitasse em torno.
No plano ideológico-filosófico, Durkheim identifica o utilitarismo como elemento que conferiu densidade ao processo econômico naquela situação histórica específica.

O utilitarismo, doutrina estruturada por Jeremy Bentham (1748-1832) e John Stuart Mill (1806-1873) na primeira metade do século 19 , forte tributário do racionalismo, considerava que toda decisão humana se apoiava em um cálculo de utilidade com relação à sua consequiência, ou resultado, na direção do bemestar entre os envolvidos. Bentham (1984) explica:

Por princípio de utilidade, entendemos o princípio segundo o qual toda ação, qualquer que seja, deve ser aprovada ou rejeitada em função se sua tendência de aumentar ou reduzir o bem-estar das partes afetadas pela ação [...]. Designamos por utilidade a tendência de alguma coisa em alcançar o bemestar, o bem, o belo, a felicidade, as vantagens etc. $O$ conceito de utilidade não deve ser reduzido ao sentimento corrente de modo de vida com um fim imediato [...].

A ressalva de Bentham serviu de profecia. Fundindo-se ao processo de divisão social do trabalho e ao individualismo, o utilitarismo se estabeleceu como cultura instalando o imediatismo em torno de resultados, a depreciação da moral em função da ação e sua conseqüência, o sacrifício, de um indivíduo ou segmento, como recurso justo, se compreendido como necessário para o benefício de todos - o que acabou sendo o sacrifício de um grupo para o benefício de outro.

$\mathrm{Na}$ economia, o utilitarismo consolidou a idéia de que os indivíduos tomam decisões sempre racionais buscando maximizar seus ganhos e lucros. E, traduziu bem-estar e felicidade em conforto material. Fazendo 'acumulação' tomar o significado de prosperidade e, fazendo 'crescimento', o de desenvolvimento.

Neste instante, ocorre uma passagem fundamental, a nosso juízo, para a compreensão de por onde passou a acomodação da contradição instalada entre a solidariedade necessária para a constituição da sociedade e a acumulação privada de capital. O somatório cumulativo entre a noção de liberdade individual liberal, a divisão social do trabalho, as pretensões sociais e políticas burguesas, o individualismo, as possibilidades tecnológicas da Revolução Industrial e o utilitarismo compuseram o ambiente da apartação entre trabalho e trabalhador.

Esta concepção separou, na cabeça das pessoas, o trabalho - que passou a figurar entre outros fatores de produção, na mesma altura do capital e da terra do trabalhador, ser humano com uma dada função econômica e elemento fundante da sociabilidade necessária, inclusive para o fluxo econômico. Assim, a idéia de 'força de trabalho' passou a simbolizar esta abstração e ser concebida como mercadoria, exata- 
mente como qualquer outra, subordinada a toda e qualquer suposta lei econômica. Portanto, trabalho e trabalhador, já que inseparáveis, foram reduzidos a insumo e elemento de custo que precisa ser otimizado para gerar a maximização da rentabilidade.

Com a apartação entre trabalho e trabalhador, no contexto cultural utilitarista, tornou-se plenamente justificável o recurso do desemprego - ou mais amplamente, da exclusão social, e política, - como estratégia de acumulação de capital de alguns. Como se isso não implicasse na desestabilização da unidade familiar, considerada como pilar da sociedade e da própria economia. Como se isso não concorresse para a diminuição da força de trabalho ativa, que gera a riqueza da nação. Como se isso não rebaixasse a qualidade de vida geral, com a geração de miséria, violência e degradação ambiental, aumentando os custos econômicos de gestão dos equipamentos públicos. Como se isso não afetasse o próprio pacto societário e a própria razão de ser da sociedade, de garantir sobrevivência e segurança aos seus associados.

No entanto, recorrer ao 'corte de pessoal', como cortar qualquer insumo produtivo, é tido como uma atitude racional. Absolutamente coerente com o suposto liberal, enunciado por Adam Smith (1723-1790), em 1776, de que a maximização do interesse coletivo se alcança exatamente quando cada indivíduo busca maximizar os seus ganhos particulares. Tese contraditada com consistência por John $\mathrm{Nash}^{10}$ a partir da aplicação da Teoria dos jogos na economia - retomando a centralidade da cooperação no processo socioeconômico. Neste ponto, a noção de "solidariedade orgânica" de Durkheim precisa da assessoria do conceito de "hegemonia" de Gramsci (1999; 2002), para explicar que tal solidariedade ocorre, não por livre adesão, mas por uma combinação de consenso e coerção.

Durkheim (2007, p. 158) aprofunda a crítica ao utilitarismo e à economia clássica, dizendo que "A economia clássica criou um mundo econômico que não existe", gerando a desregulação econômica e superdimensionando instituições econômicas particulares. E acrescenta que "A vida econômica não nasceu da vida individual, ao contrário, foi a segunda que nasceu da primeira."

Sumariamente, diríamos que a racionalidade da calculabilidade utilitária, particularmente aplicada à economia, reduz o ser humano a uma peça produtiva descartável, reeditando o darwinismo da lei do mais forte, desumanizando profundamente a sociabilidade em que vivemos.

Racionalidade e calculabilidade não consideram que os seres humanos adoecem, vivem neuroses e psicoses, crêem, envelhecem, necessitam de relações confiáveis e que são profundamente interdependentes, tanto em sua sustentação física quanto emocional. Consideram apenas os aspectos humanos que concorrem para a acumulação de riqueza e poder, chegando a precificar relações e pessoas.

$\mathrm{Na}$ verdade a 'desumanização' da economia é uma possibilidade humana, uma construção abstrata a partir de um processo de alienação do homem com relação a suas próprias projeções na natureza e nos outros indivíduos, passando a admitir sua própria reificação (MARX, 1987a; b).

\section{Cooperação e competitividade}

Como vimos não há antagonismo entre competição e cooperação. Ao contrário, estas duas estratégias quase sempre ocorrem de maneira complementar. No entanto, identificamos que há uma mudança de qualidade nos resultados de um processo hegemonizado pela cooperação de outro, hegemonizado pela competição, mesmo encontrando combinações intermediárias entre as duas estratégias.

A competição é boa de dois pontos de vista: ela permite [...] escolher o que mais nos satisfaz pelo menor preço; e ela faz com que o melhor vença [...]. (Mas) o que acontece com os empresários e empregados das empresas que quebram? [...] o capitalismo produz desigualdade crescente, verdadeira polarização entre ganhadores e perdedores. Enquanto os primeiros acumulam capital, galgam posições e avançam nas carreiras, os últimos acumulam dívidas pelas quais pagam juros cada vez maiores, são demitidos [...] tornam-se inempregáveis [...] (SINGER, 2002, p. 8).

Nos processos onde a combinação cooperaçãocompetição é presidida pela competição, a tendência é de exclusão dos 'derrotados', enfraquecendo o ambiente sistemicamente, ou seja, todos perdem. Nos processos onde a combinação é presidida pela cooperação, a tendência é a alternância de liderança ou consolidação de uma liderança sem exclusão que provoque perda sistêmica, mantendo a diversidade e a riqueza de possibilidades de interações que levem à sinergias positivas ou "causação circular cumulativa” ascendente (MYRDAL, 1965).

No esporte, onde o que ganha visibilidade é a idéia da competição, há cooperação antes da competição, para construir um marco regulatório e institucional da disputa através de acordo em torno de regras, que tornem a vitória algo reconhecido por todos e que agregue valor ao sistema, fazendo com que todos ganhem.

A economia quando, mesmo localmente, presidida pela cooperação, como na experiência já relatada de Mondragón, torna possível processos de recuperação de regiões antes deprimidas economicamente. Tal percepção tem dado grande atratividade a idéias como clusters, arranjos, aglomerados e sistemas pro- 
dutivos. E esta é uma tendência que transborda a economia e remete a uma expectativa de resgate da valoração da integralidade humana e seus valores positivos, nas mais diversas atividades da sociedade.

Entendemos que a cooperação econômica é uma construção cultural estratégica baseada na interação social, em que os objetivos são comuns, as ações são compartilhadas e os benefícios são distribuídos com equilíbrio por todo o sistema. A atual hegemonia da competição como estratégia, mesmo quando fundada na idéia da dessemelhança entre os seres humanos - que justificaria a riqueza de uns diante do determinismo da pobreza de outros - significa cair na ilusão de que a exclusão social 'purifica' ou 'qualifica' a sociedade. Na verdade, os 'excluídos' não são excluídos do sistema, eles ficam no sistema, pesando como força de trabalho inativa e demandante de serviços de educação, assistência, saúde e segurança. Oneram o Estado, além de contribuir, com outros fatores, para a geração de ambiente propício à violência social e organizada, depreciando a qualidade de vida de todos, sem exceção.

Contudo, quando a competição está subordinada à cooperação, cumpre um papel imprescindível de mobilização de forças novas e inovadoras, únicas capazes de fazer o sistema ganhar, com saltos de qualidade. A cooperação pura, sem qualquer mediação com estratégias competitivas subordinadas, leva à estagnação e à perda de qualidade, nivelando o sistema por baixo.

Como os valores mais altos de sobrevivência, estão, segundo Darwin (SOLLER, 2003), na inteligência, no senso moral e na cooperação social, o ideal seria criar possibilidades de desenvolvê-los na sociedade. E, assim, contribuir para intensificar o respeito mútuo, a solidariedade e a amizade, sem abrir mão de empreendimentos bem administrados e competitivos no sentido de sua própria sustentabilidade.

Podemos compreender que, ao participarmos do jogo econômico, concebendo-o como um componente da vida, o principal valor está na oportunidade de conhecer melhor nossas próprias habilidades e potenciais e então cooperar para que os outros realizem o mesmo. Para Barreto (2004), os jogos cooperativos se desenvolvem a partir de cinco princípios fundamentais: inclusão, coletividade, igualdade de direitos e deveres, desenvolvimento humano e a processualidade, ou estratégia. A partir desta reflexão pedagógica, inferimos algumas possibilida des para o aumento da competitividade, com estratégias econômicas cooperativas, principalmente em 'aglomerados', como expressão mais intensa do que ocorre na sociedade.

As raízes da cooperatividade já estão manifestas em Adam Smith (1723-1790):

Esse grande aumento da quantidade de trabalho que, em conseqüência da divisão do trabalho, o mesmo número de pessoas é capaz de realizar, é devido a três circunstâncias distintas: em primeiro lugar, devido à maior destreza existente em cada trabalhador; em segundo, à poupança daquele tempo que, em geral, seria costume perder ao passar de um tipo de trabalho para outro; finalmente, à invenção de máquinas que facilitam e abreviam o trabalho que, de outra forma, teria de ser feitas por muitas [...]o casaco de lã, por exemplo, que o trabalhador usa para agasalhar-se é o produto do trabalho conjugado de uma multidão de trabalhadores. O pastor, o selecionador de lã, o cardador, o tintureiro, o fiandeiro, o tecelão, o pisoeiro, o confeccionador de roupas, além de muitos outros [...] (SMITH, 1988, p.19/22).

Fica aqui claro, que as raízes da divisão do trabalho, que abriram a possibilidade do capitalismo, ao mesmo tempo multiplicaram as interdependências entre os indivíduos, aprofundando a necessidade de cooperarem entre si. Nesta relação, viram-se obrigados a estabelecer um círculo muito maior de trocas, e, portanto, de relações humanas confiáveis, o que significa solidariedade, para obterem o que precisam para seu conforto material, espiritual, afetivo e social.

"A taxa de lucro cai, não por explorar-se menos o trabalho, e sim por empregar-se menos trabalho em relação ao capital aplicado" (MARX, 1987b, p. 283). Ora, esta citação permanece válida se considerarmos que o único fator de produção capaz de gerar mais-valia é a força de trabalho. Se é possível que surja um resultado diferente em uma empresa específica - em função de uma possível composição tecnológica que exploraria, sobretudo, a "mais-valia relativa" (MARX, 1987a) - na magnitude agregada da economia, esta formulação ganha, ao nosso ver, validade lógica inconteste. Particularmente se percebemos a interdependência e as interações entre agentes e fatores de produção como a sinergia do fenômeno econômico, tal como estamos tentando fazer neste trabalho. 
Identificamos que, ao descrever o processo da "causação circular cumulativa”, Myrdal trabalha evidentemente com as relações entre agentes e fatores. Portanto, subjaz na elaboração deste autor a cooperação como condição intrínseca necessária para que ocorra a causação circular positiva ou ascendente.

Quando todo o sistema começa a mover-se, depois desse choque (intervenção externa, governamental, p. ex.), as mudanças que se operam nas forças atuam na mesma direção, o que não é a mesma coisa. Isto ocorre porque as variáveis se entrelaçam de tal sorte, em processo de causação circular, que a mudança em qualquer delas provoca alteração nas outras, estas fortificam as primeiras, seguindo-se efeitos terciários sobre aquela primeira variável afetada, e assim sucessivamente (MYRDAL, 1969, p. 40).

Ora, se o 'choque' dado no sistema, não induzir entre os agentes a perspectiva de objetivos comuns, em que todos ganham - ou vier acompanhado de outros mecanismos que façam tal indução - ocorreria um atrito também cumulativo, até que conseguisse frear, e parar, a roda da causação circular. $\mathrm{Ou}$ ainda, a cooperação como percepção do 'jogo de ganha-ganha' por parte dos agentes - os que fazem a roda continuar a mover-se, ou não - funciona como um lubrificante necessário para diminuir o atrito entre as engrenagens. Mas um lubrificante muito especial, que não só diminui o atrito como até pode acelerar o giro da causação, mesmo após cessada a intervenção exógena no dado sistema econômico.

Hirschman (1976, p. 14) ao apresentar sua teoria dos "efeitos em cadeia", promete, e cumpre, um conceito "mais inclusivo para ser usado na consideração de algumas seqüências de desenvolvimento selecionadas", referindo-se, sobretudo, a situações de subdesenvolvimento que estudou como poucos:

[...] uma atividade com muitos elos diretos com o resto da economia, por seus efeitos em cadeia retrospectivos e prospectivos, ou mais simplesmente porque se localiza na região central de um país e é realizada por produtores que possuem íntimos laços com uma vasta rede de comerciantes e habitantes da localidade: com tantas relações de amizade a sua atividade não será submetida a severas taxações.

Na tentativa de demonstrar a diferença da incidência da capacidade estatal de tributar entre 'enclaves', mais desprotegidos pela baixa interação com a sociedade local, e 'cadeias', como na citação, Hirschman revela o peso que atribui às "laços íntimos" e "relações de amizade" com "redes" e "habitantes da localidade". Como no texto o autor está se referindo a sua tese dos "efeitos em cadeia de natu- reza fiscal", estes elementos surgem com forte conotação política. Isto só reforça as evidências de que, para Hirschman, a cooperação entre os agentes econômicos é um elemento relevante para o grau de eficácia e reprodução dos efeitos em cadeia, embora ele alerte que isto também pode ensejar uma cooperação perniciosa ao conjunto do sistema, quando a cooperação se limita a uma dada corporação ou setor, em detrimento da competitividade do sistema.

Enfatizamos que a cooperação - tomados os cuidados indicados por Hirschman - é um fator que altera qualitativamente as estratégias de desenvolvimento econômico, como já vimos, em regiões e cadeias produtivas. No entanto, é na noção de aglomerados econômicos de hoje, que esta perspectiva se torna mais visível enquanto teoria e experimento empírico.

\begin{abstract}
Com base em levantamentos numa ampla variedade de setores, constatamos que a tecnologia da informação está alterando as regras da competição de três maneiras. Primeiro, seus avanços estão mudando a estrutura setorial. Segundo, a tecnologia da informação é uma alavanca cada vez mais importante à disposição das empresas para criar vantagem competitiva [...] à medida que os concorrentes imitam as inovações estratégicas dos líderes. Por fim, a tecnologia da informação está disseminando negócios completamente novos (PORTER, 1999, p. 94).
\end{abstract}

Esta citação sob o sugestivo título Mudando a natureza da competição atualiza com grande objetividade a percepção das alterações que estão ocorrendo, neste momento, no fenômeno econômico.

\begin{abstract}
Muitas mudanças no sistema de conhecimento da sociedade influem diretamente nas operações comerciais. Esse sistema de conhecimento é uma parte ainda mais difusa do ambiente de toda firma do que o sistema bancário, o sistema político, ou o sistema energético [...] Sem falar no fato de que nenhuma firma poderia abrir as portas se não houvesse linguagem, cultura, dados, informações e conhecimento técnico. De fato, o conhecimento (às vezes só informação e dados) pode ser usado como substituto de outros recursos.O conhecimento em princípio, inexaurível - é o substituto fundamental (TOFFLER, 1995, p.109).
\end{abstract}

O conhecimento é um bem que, ao contrário dos demais, cresce quanto mais é dividido. É exatamente aí que ocorre a transformação da natureza da competição. A partir de uma 'economia do conhecimento' se estabelece a lógica de quanto mais se partilha mais se acumula. Com um ganho adicional de qualidade nas relações humanas agora includentes, social e economicamente. "A habilidade de compartilhar atividades é uma base poderosa para a estratégia 
corporativa, pois o compartilhamento geralmente acentua a vantagem competitiva, através da redução do custo e do reforço da diferenciação" (PORTER, 1999, p.154).

Já quando se refere à competitividade de aglomerados, Porter (1999, p. 210-211) deixa claro seu entendimento sobre a relação cooperaçãocompetitividade.

[...] as políticas macroeconômicas são condições necessárias, mas não suficientes, para fomentar a competitividade [...]. Os aglomerados [...] constituem o foro que possibilita novas e imprescindíveis modalidades de diálogo entre empresas, órgãos governamentais e instituições

Ou seja, para Porter (1999, p. 211), a economia deve ser tratada como no esporte, onde a competição se dá subordinada à consolidação da cooperação em torno dos termos regimentais e regulatórios que servirão de arcabouço político, ético e institucional para que a competição, seja qual for seu resultado, contribua para a melhoria do ambiente sistemicamente. "Assim, os aglomerados seriam definidos como um sistema de empresas e instituições inter-relacionadas, cujo valor como um todo é maior do que a soma das partes."

Sintetizamos, sob nossa versão, os principais valores agregados pelas estratégias de cooperação econômica, entre elas os aglomerados, no quadro 1 a seguir.
No quadro 1 procuramos evidenciar como um valor, tido muitas vezes como apenas ético ou moral, projeta-se estrategicamente também como valor econômico, às vezes especificamente financeiro, a conferir maior competitividade ao conjunto do sistema e às corporações e instituições que lhes fazem parte.

No entanto, julgamos de grande importância a compreensão da afirmação de Porter de que "o valor do conjunto é maior do que a da soma das partes". É preciso perceber o sinergismo entre as estratégias cooperativas e entre os valores que agregam.

Contudo, a maximização dos resultados possíveis com a adoção do valor 'confiança', só se alcança quando na outra ponta encontramos um parceiro comercial que adota o valor da 'credibilidade', por seu turno. Ora, se por um lado procura-se apostar na seriedade e capacidade produtiva do parceiro e por outro, temos alguém comprometido com a qualidade de sua oferta e com os termos do contrato, o resultado tende a ser muito positivo, tanto economicamente quanto pelo que representa de qualidade de vida.

Se a adoção destes valores acumula a adoção de novos valores cooperativos, a tendência é ampliar ainda mais os resultados materiais e imaterias, econômicos, sociais, políticos e culturais. O que jamais seria possível alcançar isoladamente por apenas uma das partes, ou sob um sistema presidido pela competição pura.

\section{Quadro 1 - Valores agregados proporcionados pela cooperação}

\begin{tabular}{|c|c|c|c|}
\hline Valor & Benefícios & Estratégia Operacional & Resultados \\
\hline Confiança & $\begin{array}{l}\text { Transações mais seguras, satis- } \\
\text { fação com o atendimento }\end{array}$ & $\begin{array}{l}\text { Eliminação de etapas de contro- } \\
\text { le excessivo }\end{array}$ & $\begin{array}{l}\text { Redução de custo de transa- } \\
\text { ção e maior agilidade }\end{array}$ \\
\hline Credibilidade & Respeito e reconhecimento & $\begin{array}{l}\text { Garantia de qualidade e demais } \\
\text { termos do contrato }\end{array}$ & $\begin{array}{l}\text { Estabilidade comercial e sus- } \\
\text { tentabilidade de longo prazo }\end{array}$ \\
\hline Partilha & $\begin{array}{l}\text { Conhecimento acumulado se } \\
\text { multiplica socialmente }\end{array}$ & $\begin{array}{l}\text { Compra conjunta de insumos, } \\
\text { MKT articulado, formação e } \\
\text { treinamento em parceria, deman- } \\
\text { das políticas }\end{array}$ & $\begin{array}{l}\text { Maior poder de barganha e } \\
\text { pressão, menor custo de MKT } \\
\text { e treinamento, acesso a políti- } \\
\text { cas públicas }\end{array}$ \\
\hline Relacionamento & $\begin{array}{l}\text { Pluralidade e complementarie- } \\
\text { dade }\end{array}$ & $\begin{array}{l}\text { Negociação, articulação em re- } \\
\text { des }\end{array}$ & Fidelização \\
\hline Identidade & Objetivos comuns & $\begin{array}{l}\text { Interação institucional perma- } \\
\text { nente }\end{array}$ & Enraizamento cultural \\
\hline Solidariedade & $\begin{array}{l}\text { Maior aquecimento econômico } \\
\text { e qualidade de vida }\end{array}$ & $\begin{array}{l}\text { Inclusão permanente de agen- } \\
\text { tes e instituições, compras lo- } \\
\text { cais prioritárias }\end{array}$ & $\begin{array}{l}\text { Ampliação da base de susten- } \\
\text { tação, maior produção e con- } \\
\text { sumo }\end{array}$ \\
\hline
\end{tabular}

Fonte: Arroyo (2007) 
Como obter, livre fluxo de informações sem confiança e uma forte convicção da contribuição da cooperação para a competitividade?

Articulando as idéias de conhecimento, fluxo de informações e de inteligência como expressão do composto cultura e território, vemo-nos diante de uma questão incontornável: a educação.

Sendo o trabalho que define a existência humana [...] a educação não é algo de fora para dentro, que acontece apenas em cursos de capacitação [...]. Não é sinônimo de ensino, mas se dá em diferentes espaços e tempos da formação humana. Fundamentalmente, é parte integrante da cultura do trabalho que vai se constituindo no cotidiano da produção associada e nas relações que [...] estabelecem com o mundo lá fora. Por isto, dizemos que a prática é a fonte de conhecimento e que o trabalho é instância e é, ao mesmo tempo, princípio educativo (TIRIBA, 2006).

A experiência do Complexo Cooperativo de Mondragón, tal como descrito por Barker (1997), possui forte presença do componente educacional em toda sua história e em toda sua estratégia organizacional, criando escolas e universidades vinculadas à sua estratégia mercadológica.

Este componente surge com destaque nas considerações de Porter $(1999$, p. 245) sobre as condições dos aglomerados em condições de países em desenvolvimento, principalmente se tomarmos a educação como na citação anterior de Tiriba:

O desenvolvimento de aglomerados que funcionem bem é um dos passos essenciais na evolução para uma economia avançada. Nas economias em desenvolvimento, a formação dos conglomerados é inibida pelo baixo nível de educação e de qualificação do pessoal local, pelas deficiências tecnológicas, pela falta de acesso ao capital e pelo subdesenvolvimento das instituições. Às vezes, as políticas governamentais também atuam contra a formação dos aglomerados. As restrições relativas à localização industrial e aos subsídios provocam uma dispersão artificial das empresas. Os currículos das universidades e das escolas técnicas, estabelecidos por órgãos centrais, não se adaptam às necessidades dos aglomerados [...].

Esta precisa descrição do sinergismo negativo, que em parte vivemos no Brasil, é o construto de nossa história, cultura e de tudo o que nos conforma como.

\section{Considerações finais}

Os impactos sociais, ambientais, culturais e econômicos, que o estilo de vida das sociedades moder- nas gerou, chegaram a tal ponto que sua reversão exige uma grande e eficiente soma de esforços. Porém, articular eficientemente ações coletivas em sociedades e indivíduos que estão tão melhor treinados, e condicionados, a atuar individualmente e mais 'contra' do que 'junto com' o outro, é o maior desafio das organizações econômicas. Neste momento em que a cooperação é tão necessária, como aprender a trabalhar harmonicamente com aquele de quem nos habituamos a desconfiar?

No entanto, contrariando esta tendência, encontramos alento, principalmente em comunidades empobrecidas, onde um grande número de pessoas espontaneamente desenvolvem ações voluntárias - absolutamente anti-econômicas e, portanto, 'irracionais', segundo os clássicos - em benefício do próximo.

O medo, a desconfiança e a desmotivação impedem-nos de experimentar ultrapassar coletivamente os limites das impossibilidades individuais. Para transformar essa situação é preciso uma nova racionalidade: a racionalidade da solidariedade.

\begin{abstract}
Muito em geral poderá dizer-se que a emergência do terceiro setor significa que, finalmente, o terceiro pilar da regulação social na modernidade ocidental, o princípio da comunidade, consegue destronar a hegemonia que os outros dois pilares, o princípio do Estado e o princípio do mercado, partilharam até agora com diferentes pesos relativos em diferentes períodos [...] o princípio da comunidade afirma a obrigação política horizontal e solidária de cidadão a cidadão. Segundo ele (Rousseau), é esta a obrigação política originária, a que estabelece a inalienabilidade da soberania do povo de que deriva a obrigação política com o Estado ( SANTOS, 2006, p. 352).
\end{abstract}

Ainda segundo Santos (2006, p. 351), alguns autores como Defourny, Favreau e Laville denominam este campo de "nova economia social", ou outros como "economia social e solidária".

\section{Referências}

ANTEAG-Associação Nacional de Trabalhadores e Empresas de Autogestão, 2005. Disponível em: < $\underline{\text { http:// }}$ www.anteag.org.br>. Acesso em: jun. 2007.

ARROYO, J. T; SCHUCH, F. (Org.). Solidariedade e sucesso: a experiência do Banco do Povo de Belém. Editado pela Prefeitura de Belém, Pará, 2006.

Economia popular e solidária: a alavanca para um desenvolvimento sustentável. São Paulo: Fundação Perseu Abramo, 2006. 
BARKER, J. O exemplo de Mondragon. In: HESSELBEIN, F, GOLDSMITH, M, BECKHARD, R.(Org.). A organização do futuro: como preparar hoje as empresas de amanhã. São Paulo: Ed. Futura, 1997.

BARRETO, A. V. B. Jogos cooperativos: promovendo valores solidários. Revista Intellectus, Sumaré, v. 2, n. 2, p. 48-62, 2004.

BENTHAM, J. Uma introdução aos princípios da moral e da legislação. Tradução de Luiz João Baraúna. São Paulo: Abril Cultural, 1984. (Coleção Os Pensadores).

CONDERE. Consultoria de resultados. Disponível em: <http://www.condere.com.br/>. Acesso em: ago. 2007.

DATA POPULAR. Notícias. Disponível em: <http:// www.datapopular.com.br/>. Acesso em: jul. 2007.

DURKHEIM, È. De la division du travail social (1893). Ed. Institut Nationale de la Langue Française. Disponível em: <www.dominiopublico.gov.br $>$. Acesso em 15 abr. 2007

GRAMSCI, A. Cadernos do cárcere. Edição de Carlos Nelson Coutinho, colaboração de Luiz Sérgio Henriques e Marco Aurélio Nogueira. Rio de Janeiro: Civilização Brasileira, 1999-2002.

HIRSCHMAN, A. O desenvolvimento por efeitos em cadeia. Uma abordagem generalizada. Novos Estudos CEBRAP, São Paulo, n.18, out./dez., 1976.

Conflitos sociais como pilares da sociedade de mercado democrática, 1994. Novos Estudos CEBRAP, São Paulo, n. 42, jul.1995.

MARX, K. O capital: crítica da economia política. São Paulo: Bertrand Brasil, DIFEL, 1987a, v. 1.

Salário, preço e lucro. Tradução de Olinto Beckeman. São Paulo: Global, 1987b, v. 4.

MYRDAL, G. Teoria econômica e regiões subdesenvolvidas. Rio de Janeiro: Ed. Saga,1965.

theon, 1969

Objectivity in Social Research. New York: Pan-

PORTER, M. Competição: estratégias competitivas essenciais. Rio de Janeiro: Ed. Campus, 1999.

SANTOS, B. de S. A gramática do tempo: para uma nova cultura política - Para um novo senso comum: a ciência, o direito e a política na transição paradigmática. São Paulo: Cortez, 2006, v. 4.
SINGER, P. Introdução à economia solidária. São Paulo: Fundação Perseu Abramo, 2002.

SMITH, A. A riqueza das nações. Os Economistas Livro I. São Paulo: Nova Cultural, 1988.

SOLLER, R. Jogos cooperativos para a educação infantil. Rio de Janeiro: Ed. Sprint, 2003.

TIRIBA, L. O lugar da economia solidária na educação e o lugar da educação na economia solidária. Palestra proferida no IV Encontro Internacional de Economia Solidária, São paulo, NEOL/USP, 2006.

TOFFLER, A. A terceira onda. Rio de Janeiro: Record, 1995.

\section{Notas}

1 Segundo a consultoria Kanitz e Associados apenas 7\% dos jovens brasileiros fazem algum tipo de trabalho voluntário. Em contrapartida, a mesma fonte apresenta que $54 \%$ gostariam de ser voluntários, o que pode ser comprovado pelo Dossiê Universo Jovem - MTV (uma pesquisa que a MTV realiza regularmente e divulga nos meios de comunicação) que apresentou $36 \%$ como já tendo participado de alguma campanha filantrópica e $41 \%$ já tendo feito doações a entidades carentes. $\mathrm{O}$ conceito de trabalho voluntário, no Brasil, está definido pelaLein ${ }^{\circ}$ 9.608, de 18. 2.1998.

2 O primeiro setor é o governo, que é responsável pelas questões sociais. O segundo setor é o privado, responsável pelas questões individuais. O terceiro setor é constituído por organizações sem fins lucrativos e não governamentais, que tem como objetivo gerar serviços de caráter público. No Brasil, são mais de 250 mil organizações, que movimentam $\mathrm{R} \$ 12$ bilhões/ano, oriundos da prestação de serviços, do comércio de produtos e da arrecadação de doações. O valor corresponde a 1,2\% do PIB brasileiro e demonstra enorme potencial de crescimento, pois o setor já movimenta $6 \%$ do PIB em países da Europa e nos EUA, segundo o portal Setor 3 doSENAC.

3 Diz respeito a um conjunto plural de iniciativas pedagógicas não-formais que visam a formação cidadã, sociopolítica, e têm como público principal jovens e adultos. Cumpre papel central na formação de lideranças sociais desde o período do combate à ditadura militar (1964) até hoje, na perspectiva do aprofundamento da democracia.

4 Diz respeito a uma das principais estratégias de aprofundamento da democracia atualmente. Para além da participação na elaboração das políticas públicas, introduz a necessidade do acompanhamento da execução das mesmas, comoelemento central da nossa nova cultura política nacional. 
5 Regime produtivo em que os trabalhadores são donos de seus próprios meios e responsáveis pela administração da própria organização econômica.

6 Doutrina político-econômica baseada principalmente na defesa da minimização do Estado e na livre regulação da sociedade pelo mercado. Ganhou hegemonia global no período Reagan -Thatcher, quando induziu a onda de privatizações e flexibilização da legislação trabalhista nas décadas 1980/1990.

7 O Acordo de Basiléia foi firmado pelo G-10 em 1988 em documento intitulado International Convergence of Capital Measurement and Capital Standards, quando os países desenvolvidos impuseram ao resto do mundo os seus parâmetros de cálculo de risco para operações financeiras incluindo o crédito.

8 Localidades medievais, embriões urbanos às vezes fortificados, onde diversos agentes econômicos não-nobres, principalmente vilões (senhores intermediários sem títulos) se encontravam para poder exercer o comércio livrementelonge do controle da coroa e da igreja, que então condenava o lucro. De onde se originou o termo 'burguês'.

9 Émile Durkheim(1858-1917)é consideradoum dos pais da sociologia moderna. Durkheim foi o fundador da escola francesa de sociologia, posterior a Mafuso, que combinava a pesquisa empírica com a teoria sociológica. Éreconhecido amplamente como um dos melhores teóricos do conceito da coesão social.

10 Prêmio Nobel de Economia em 1951 pelo trabalho Jogos Não-Cooperativos onde expunha a possibilidade de ocorrência de mais de uma solução de equilíbrio em uma dada situação competitiva, e que estas soluções dependiam de cooperações entre os envolvidos.

\section{João Cláudio Tupinambá Arroyo}

Professor na Faculdade do Pará (FAP)

Mestre em Economia pela Universidade da Amazônia

Membro do Conselho Curador da Fundação Perseu Abramo e do Fórum Brasileiro de Economia Solidária

\section{Faculdade do Pará (FAP)}

Rua Municipalidade, 839

Bairro Reduto

Belém - Pará

CEP: 66053-000 